\title{
Analysis of SGOT, SGPT, and IgM anti PGL-1 in Multibacillary Leprosy Patient after Multi Drug Therapy
}

\author{
Farida Tabri ${ }^{1}$, Zainuddin Maskur ${ }^{1}$, Muhammad Dali Amiruddin ${ }^{1} \&$ Harry L. Makalew ${ }^{1}$ \\ ${ }^{1}$ Department of Dermatology and Venereology, Faculty of Medicine, Hasanuddin University, Makassar, \\ Indonesia \\ Correspondence: Farida Tabri, Department of Dermatology and Venereology, Faculty of Medicine, Hasanuddin \\ University, Makassar, Indonesia. Tel: 62-812-420-8996.
}

Received: May 15, 2017 Accepted: June 12, 2017 Online Published: June 19, 2017

doi:10.5539/gjhs.v9n9p36 URL: https://doi.org/10.5539/gjhs.v9n9p36

\begin{abstract}
Introduction: Leprosy is a fairly dreaded disease, but it is curable. However, liver failure is one of the side effect of the treatment that challenging to manage.

Objectives: Assessing the effects of Multi Drug Therapy (MDT) on the liver function (SGOT, SGPT) and Mycobacterium Leprae Particle Agglutination (MLPA) test (IgM anti PGL-1) before and after treatment in patients with multibacillary (MB) leprosy.

Method: Twenty-eight patients who met the inclusion criteria were enrolled in this study which categorized as new MB leprosy patients in Dr. Wahidin Sudirohusodo Hospital, Makassar, Indonesia. In order to test the liver function, blood serum was taken to measure the SGOT and SGPT level with Bochringer Mannheim automatic analysis, while MLPA test measurement was performed with qualitative method. Blood serum was collected three times with the following period; before the treatment, 3 months, and 6 months after treatment. The data was analyzed using Friedman and Wilcoxon Signed Rank test with significant level $\mathrm{p}<0.001$.
\end{abstract}

Result: There were significant increases in SGOT and SGPT levels $(\mathrm{p}<0.001)$ before and after MDT treatment between 3 to 6 months. Meanwhile, for IgM anti PGL-1, it was not significant ( $>0.01$ ) before treatment and after 3 months treatment, but significant different $(\mathrm{p}<0.001)$ on 6 months treatment.

Conclusion: MDT treatment on MB leprosy patient increase the SGOT and SGPT level but decrease the IgM anti PGL-1 after the 6 months of treatment.

Keywords: IgM anti PGL-1, multibacillary leprosy, Multi Drug Therapy, SGOT, SGPT

\section{Introduction}

Leprosy is a chronic granulomatous disease, which mainly affecting the skin, peripheral nerves and mucosa of the upper respiratory tract. Leprosy is caused by Mycobacterium leprae (M. leprae), an obligate intracellular bacterium. Manifestations of clinical symptoms have a broad spectrum, which classified as Tuberculoid (TT), Borderline Tuberculoid (BT), Borderline Borderline (BB), Borderline Lepromatous (BL) and Lepromatous Leprosy (LL). (Gaschignard et al., 2016).

Clinical manifestations of leprosy very various and among other diseases, it was known as the great imitators therefore it could imitate clinical symptoms of many diseases. These manifestations of leprosy depends on individual immunity response to $M$. leprae and it has a lot of similarity between patient with leprosy and connective tissue diseases both clinically and serologically (Hsieh \& Wu, 2014).

Main purpose in leprosy eradication is to cut the chain of infection in order to decrease it's incidence, by treating and curing patients and also prevent the risk of disability (Ribeiro et al., 2015). Thus, in order to achieve these objectives, the principal strategy is still based on the early detection and treatment. Since introduced by WHO in 1982, multidrug therapy (MDT) has become a treatment strategy that has provided a highly effective cure for leprosy (WHO Expert Committee on Leprosy, 2012).

Among of side effect MDT drugs regiment is hepatotoxic and the simple examination to assess it is by measuring liver function through SGOT and SGPT tests (Amacher et al., 2013; Robles-Diaz et al., 2014). Progress in the field of immunology is very helpful in making the diagnosis and treatment including the use of serological tests for 
leprosy (Setia et al., 2011). One of the serological test to assess IgM anti PGL-1 is Mycobacterium Leprae Particle Agglutination (MLPA). It is not only a simple and economical technique for early diagnosis and evaluation of leprosy treatment but also has high specificity and sensitivity (Eichelmann et al., 2013; Widodo, 2015).

The objective of this study is to analyze the liver function (SGOT, SGPT) and MLPA test (IgM anti PGL-1) in patient with MB leprosy before, 3 months, and 6 months after treatment with MDT-WHO regiment.

\section{Material and Methods}

This was a cohort study of 28 subjects, they are new patients with MB leprosy who visited Dr. Wahidin Sudirohusodo Hospital in Makassar, Indonesia. The subjects consist of 19 men (mean age 27.9 years) and 9 women (mean age 25.8 years). Venous blood $(5 \mathrm{cc})$ was collected after the patient signed the informed consent. To assess the liver function, the blood was centrifuged to obtain serum than SGOT and SGPT measurement was performed. The examination was conducted by automated Bochringer Mannheim analyser. While to assess MLPA test (IgM anti PGL-1) we assessed qualitatively using blood serum. This study was approved by the ethical committee of Faculty of Medicine, Hasanuddin University.

Statistical analysis was performed using SPSS 20.0.1 package for Windows (SPSS Inc., Chicago, IL, USA). The Friedman and Wilcoxon Signed Rank tests were used to analyze the significant difference of SGOT, SGPT and MLPA test (IgM anti PGL-1) before, 3 months, and 6 months after treatment. A value of $p<0.001$ was considered statistically significant.

\section{Results}

Based on WHO classification, 28 patients were enrolled in this study can categorized as multibacillarry leprosy: 4 BB-type patients (14.29\%), 17 BL-type patients (60.71\%) and 7 LL-type patients (25.00\%).

The result of this study showed that both SGOT and SGPT were increased after MDT treatment. Friedman test result was supported this finding by significant difference of SGOT and SGPT $(p<0.001)$ before and after treatment (Table 1 and Figure 1). Further statistical analysis using Wilcoxon Signed Rank test showed significant difference $(p<0.001)$ between before and 3, 6 months after treatment, but not for between 3 and 6 month $(p>0.001)$.

Table 1. Mean value of SGOT and SGPT from MB type leprosy patients before, after 3 months and 6 months of treatment and the result of Friedman test.

\begin{tabular}{|c|c|c|c|c|c|c|}
\hline \multirow{2}{*}{ Time } & \multicolumn{2}{|c|}{ SGOT $(\mathrm{u} / \mathrm{l})$} & \multirow{2}{*}{ Friedman test } & \multicolumn{2}{|c|}{ SGPT (u/l) } & \multirow{2}{*}{ Friedman test } \\
\hline & Mean & S D & & Mean & S D & \\
\hline Before & 17.61 & 4.72 & & 15.75 & 8.28 & \\
\hline 3 month & 24.50 & 5.32 & $\mathrm{p}<0.001$ & 19.93 & 6.91 & $\mathrm{p}<0.001$ \\
\hline 6 month & 26.07 & 6.63 & & 22.04 & 7.68 & \\
\hline
\end{tabular}




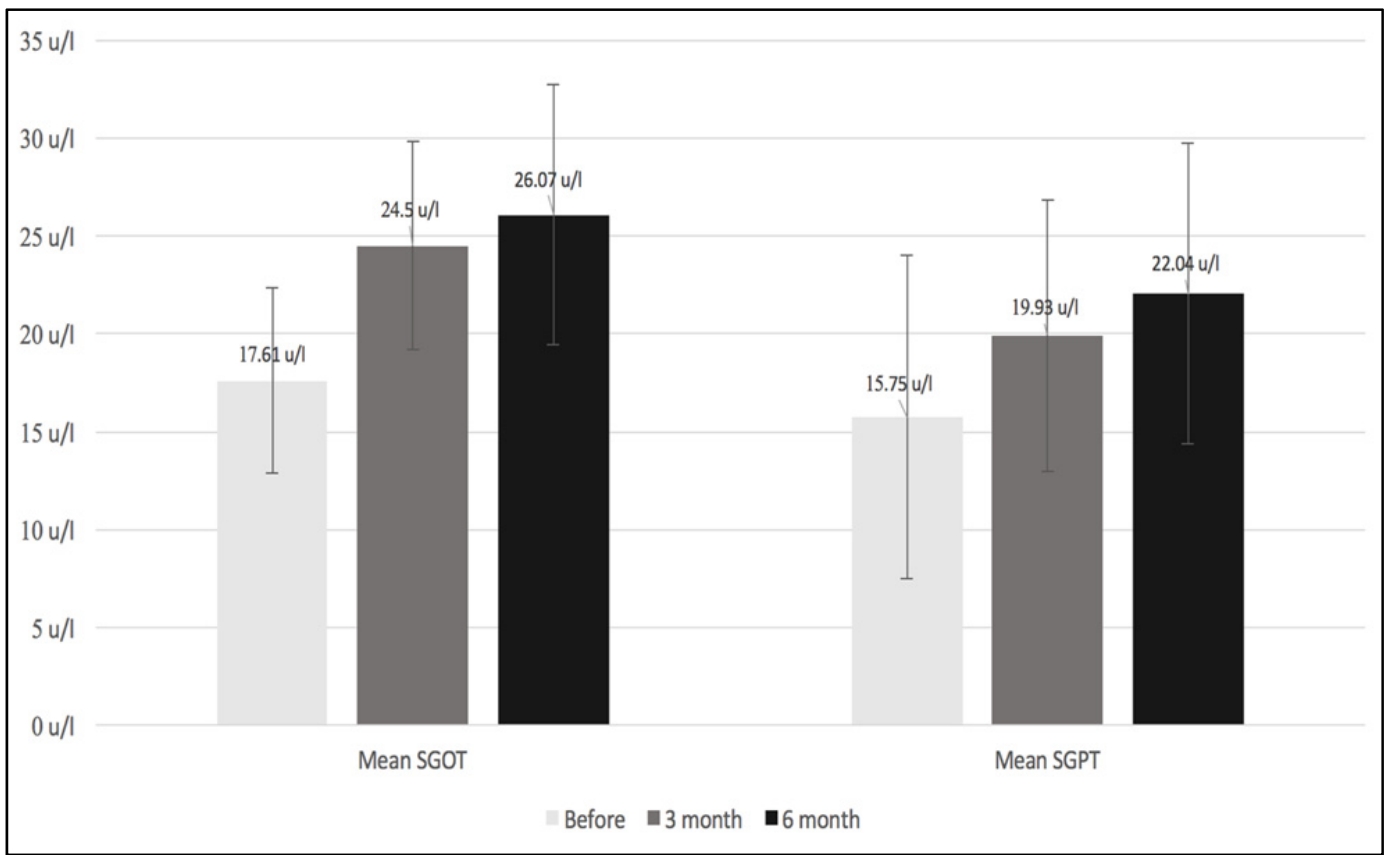

Figure 1. Mean and SD value of SGOT and SGPT from MB type leprosy patients before, 3 months and 6 months after treatment

The results of the MLPA test (IgM anti PGL-1) can be seen in Table 2 and Figure 2. Based on Friedman Test there is a significant difference during treatment $(\mathrm{p}<0.001)$. Furthermore, statistical analysis using Wilcoxon Signed Rank test showed no significant differences ( $p>0.001)$ before and 3 month after treatment. In contrast, after 6 months of treatment there was a significant difference $(p<0.001)$ compared before treatment.

Table 2. Mean value of IgM anti PGL-1 from MB type leprosy patients before, after 3 months and 6 months of treatment and the result of Friedman test

\begin{tabular}{llll}
\hline IgM anti PGL-1 & Mean & S D & Friedman Test \\
\hline Before & 187.43 & 84.76 & \\
3 month & 197.71 & 82.65 & $\mathrm{p}<0.001$ \\
6 month & 72.00 & 44.09 & \\
\hline
\end{tabular}




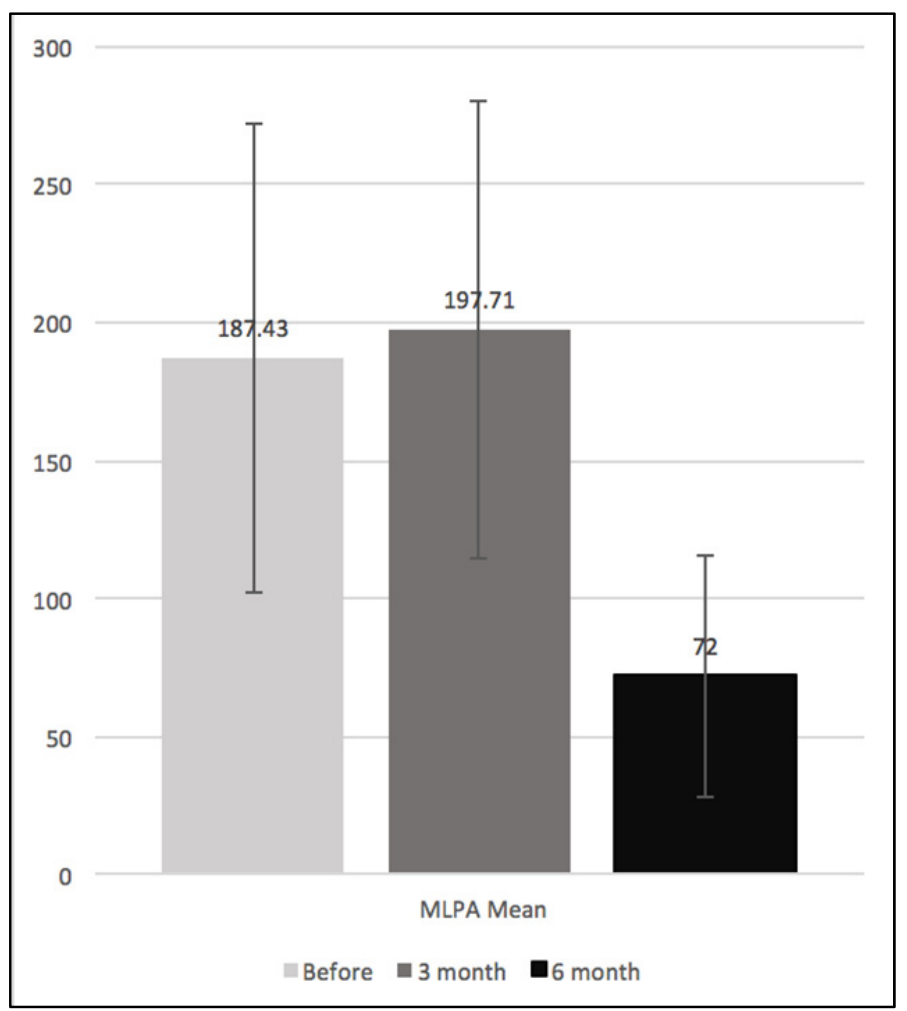

Figure 2. Mean and SD value of IgM anti PGL-1 from MB type leprosy patients before, 3 months and 6 months after treatment

\section{Discussion}

Twenty-eight leprosy patients who met the criteria of multibacillary leprosy patients (BB, BL and LL type) based on WHO classification participated in this study (WHO Expert Committee on Leprosy, 2012). All patients have not receiving any treatment before study.

Drug Induced Liver Injury (DILI) is one of the serious complications of drug therapy (Amacher et al., 2013; Borlak et al., 2014) that finally cause Acute Liver Failure (ALF) and liver transplantation (Corsini et al., 2012). The World Health Organization (WHO) (2012) recommends multibacillary type leprosy treatment using MDT that is a combination of dapsone, rifampicin, and clofazimine for 12 months to complete the treatment. Study by Deps et al. (2007) reported that $20-23.5 \%$ of patients who received MDT showed hepatic abnormalities.

Among three drugs (dapsone, rifampicin, clofazimine), rifampicin is the most important anti-leprosy and it is included in drug regimens for both paucibacillary (PB) and multibacillary (MB) types. It is also associated with the occurrence of DILI. (Borlak et al., 2014; Corsini et al., 2012). Schultz et al. (2014) found that using $600 \mathrm{mg}$ or more of rifampicin given daily was a risk factor for hepatotoxicity. Clofazimine is very effective and safe when given daily in normal doses. The use of dapsone in appropriate doses rarely gives side effects. Although there are many side effects that may result such as skin allergic reactions, hemolytic anemia, methemoglobinemia, jaundice, agranulocytosis, psychotic reactions and 'dapsone syndrome' (Deps et al., 2007).

In this present study, we found that there was a significant increases in SGOT and SGPT level after treatment compared to before treatment. According to Kamble et al. (2017), values with an upper limit of $35 \mathrm{u} / 1$ for both SGOT and SGPT level are considered normal. So, the increasing of SGOT and SGPT (3 and 6 months) after treatment were still within normal limits (Table 1). We can conclude that the administration of MDT drugs up to 6 months is safe for liver function. This also corresponds to a study where the effect of rifampicin on liver toxicity is negligible because of low SGOT and SGPT levels (Parikh et al., 2014). However, in addition to our research data, there is a significant increase in SGOT and SGPT levels after MDT therapy, thus monitoring of liver function is important to be performed regularly especially in longer term MDT therapy.

Table 2 shows the IgM anti PGL-1 levels before treatment and almost no difference 3 months after treatment and subsequently decreased significantly 6 months after treatment. In this study, we used MLPA test to detect IgM anti-PGL-1 because MLPA is a simple and economical technique for early diagnosis and evaluation of 
multibacillary leprosy treatment, and has a good specificity and sensitivity (Eichelmann et al., 2013; Geluk, 2013). The MLPA test specificity was $91 \%$ in MB leprosy patients and $21 \%$ in patients PB. The MLPA (IgM anti PGL-1) test can also be used for early detection of leprosy in order to reduce the risk of nerve damage (Geluk, 2013).

There was positive correlation between the level of IgM anti PGL-1 and the number of M. leprae in patient who appeared clinically with a large number of active lesions. Individuals with positive anti-PGL-1 IgM had a 7.2-fold higher risk of leprosy than individuals with negative anti-PGL-1 IgM. (Karim et al., 2015). The MLPA test can be used not only in diagnosing MB type leprosy cases but also for treatment evaluation (Datta et al., 2014). Our study showed that IgM anti PGL-1 was decreased 6 months after treatment, it means that the MDT regimen administered for 6 months may provide improvement in leprosy patients.

\section{Conclusion}

The administration of MDT drugs for 6 months in MB type leprosy patients increase SGOT and SGPT level although within normal limits, and also decreases the IgM anti PGL-1. Based on the results of this study we suggest that IgM anti PGL-1 can be used as markers in diagnosing and evaluating in cases of MB type leprosy patients.

\section{Acknowledgements}

The authors are gratefull to Arifin Seweng, MD, MPH, Ph.D (Department of Biostatistics, Faculty of Public Health, Hasanuddin University) to analysis statistic the data and also Ardo Sabir, DDS, Ph.D (Faculty of Dentistry, Hasanuddin University) for valuable correction of the manuscript.

\section{Financial Support and Sponsorship}

There are no financial support and sponshorship.

\section{Competing Interests Statement}

The authors declare tha there are no conflicts of interest.

\section{References}

Amacher, D.E., Schomaker, S.J., Aubrecht, J. (2013). Development of Blood Biomarkers for Drug-Induced Liver Injury: An Evaluation of Their Potential for Risk Assessment and Diagnostics. Mol. Diagn. Ther., 17, 343-354. https://doi.org/10.1007/s40291-013-0049-0

Borlak, J., Chougule, A., Singh, P.K. (2014). How useful are clinical liver function tests in in vitro human hepatotoxicity assays? Toxicol. In Vitro, 28, 784-795. https://doi.org/10.1016/j.tiv.2014.03.006

Corsini, A., Ganey, P., Ju, C., Kaplowitz, N., Pessayre, D., Roth, R., Watkins, P.B., Albassam, M., Liu, B., Stancic, S., Suter, L., Bortolini, M. (2012). Current Challenges and Controversies in Drug-Induced Liver Injury. Drug Saf., 35, 1099-1117. https://doi.org/10.1007/BF03261997

Datta, S., Pandya, S., Marfatia, Y., Rakshit, A. (2014). Clinico-Histopathological histopathological correlation and detection of anti PGL-1 antibodies in leprosy patients. Bangladesh J. Med. Sci., 13. https://doi.org/10.3329/bjms.v13i3.9153

Deps, P.D., Nasser, S., Guerra, P., Simon, M., Birshner, R., \& Rodrigues, L. C. (2007). Adverse effects from multi-drug therapy in leprosy: a Brazilian study. Lepr. Rev. 78(3), 216-222.

Eichelmann, K., González, S.G., Salas-Alanis, J., Ocampo-Candiani, J. (2013). Leprosy. An update: definition, pathogenesis, classification, diagnosis, and treatment. Actas Dermo-Sifiliográficas Engl. Ed., 104(7), 554-563.

Gaschignard, J., Grant, A. V., Thuc, N. V., Orlova, M., Cobat, A., Huong, N. T., ... Alcaïs, A. (2016). Pauci- and Multibacillary Leprosy: Two Distinct, Genetically Neglected Diseases. PLoS Negl. Trop. Dis., 10, e0004345. https://doi.org/10.1371/journal.pntd.0004345

Geluk, A. (2013). Challenges in immunodiagnostic tests for leprosy. Expert Opin. Med. Diagn., 7(3), 265-274. https://doi.org/10.1517/17530059.2013.786039

Hsieh, T.-T., Wu, Y.-H. (2014). Leprosy mimicking lupus erythematosus. Dermatol. Sin., 32, 47-50. https://doi.org/10.1016/j.dsi.2013.01.004

Kamble, R., Sodhi, K.S., Thapa, B.R., Saxena, A.K., Bhatia, A., Dayal, D., Khandelwal, N. (2017). Liver acoustic radiation force impulse (ARFI) in childhood obesity: comparison and correlation with biochemical markers. $J$. Ultrasound, 20(1), 33-42. https://doi.org/10.1007/s40477-016-0229-y 
Karim, A. (2015). The Analysis of the Mycobacterium Leprae Resistance Against Ofloxacin After the Rifampicin Ofloxacin Minocycline (ROM) Therapy. Am. J. Clin. Exp. Med., 3, 167. https://doi.org/10.11648/j.ajcem.20150304.17

Parikh, R., Patel, L., \& Dalwadi, S. (2014). Microparticles of rifampicin: comparison of pulmonary route with oral route for drug uptake by alveolar macrophages, phagocytosis activity and toxicity study in albino rats. Drug Deliv., 21, 406-411. https://doi.org/10.3109/10717544.2013.851302

Ribeiro, F. M., Gomez, V. E., Albuquerque, E. M., Klumb, E. M., \& Shoenfeld, Y. (2015). Lupus and leprosy: beyond the coincidence. Immunol. Res., 61(1-2), 160-163. https://doi.org/10.1007/s12026-014-8596-y

Robles-Diaz, M., Lucena, M. I., Kaplowitz, N., Stephens, C., Medina-Cáliz, I., González-Jimenez, A., Ulzurrun, E., Gonzalez, A. F., Fernandez, M. C., ... Andrade, R. J. (2014). Use of Hy's Law and a New Composite Algorithm to Predict Acute Liver Failure in Patients With Drug-Induced Liver Injury. Gastroenterology, 147, 109-118.e5. https://doi.org/10.1053/j.gastro.2014.03.050

Schultz, V., Marroni, C.A., Amorim, C.S., Baethgen, L.F., Pasqualotto, A.C. (2014). Risk Factors for Hepatotoxicity in Solid Organ Transplants Recipients Being Treated for Tuberculosis. Transplant. Proc., 46, 3606-3610. https://doi.org/10.1016/j.transproceed.2014.09.148

Setia, M.S., Shinde, S.S., Jerajani, H.R., Boivin, J.F. (2011). Is there a role for rifampicin, ofloxacin and minocycline (ROM) therapy in the treatment of leprosy? Systematic review and meta-analysis. Trop. Med. Int. Health, 16(12), 1541-1551. https://doi.org/10.1111/j.1365-3156.2011.02873.x

WHO Expert Committee on Leprosy (Ed.). (2012). Eighth report / WHO Expert Committee on Leprosy: [Geneva, 12 - 19 October 2010], WHO technical report series. World Health Organization, Geneva.

Widodo, O. S. Y. (2015). Aspek Mikrobiologi Pada Penyakit Tropis Yang Terabaikan (Microbiology Aspect Of Neglected Tropical Diseases). J. Saintika Med., 11(2), 90-91.

\section{Copyrights}

Copyright for this article is retained by the author(s), with first publication rights granted to the journal.

This is an open-access article distributed under the terms and conditions of the Creative Commons Attribution license (http://creativecommons.org/licenses/by/4.0/). 